Theories \& Applications, the International Edition

Printed Version : (ISSN 2090-5262)

Online Version : (ISSN 2090-5270)

July 2014, Volume 4, No. 2 Pages (85 - 88)

\title{
The Effect of a Coordination Training Program on the Performance of Basic Handball Skills among Young Female Athletes.
}

\author{
Heba Labib \\ Faculty of physical education, Helwan University, Egypt.
}

\begin{abstract}
Handball is a sport which demands a high level of coordination. The term "coordination" has been defined as the ability to perform complex motor exercises. The 5 basic coordination abilities are: reaction, rhythm, balance, kinesthetic differentiation and space - time orientation. It has been suggested that "additional technique training" should be practiced during childhood and adolescence in order enhance coordination abilities. The aim of this study was to define which elements of coordination are the most important in handball and to identify whether a coordination training program will improve the performance of basic handball skills among children. Ten expert coaches in handball completed a questionnaire relating to the five elements of coordination and gave their opinion regarding the most important elements of coordination for handball players. Based on the results from the questionnaires, a program was designed to provide practice in the most important elements of coordination for handball. The study participants were 20 female youth handball players (age $11 \pm 2$ years). The experimental group $(E G, n=20)$ performed a specific coordination program 3 times a week for 12 weeks. Measurements of handball performance were taken prior to beginning the program and again after 12 weeks of training. The results revealed that there was a significant difference in performance before and after the training program. In conclusion, performance of basic handball skills (passing, shooting, dribbling and defensive movements) improved after participating in the training program for 12 weeks.
\end{abstract}

Keywords: Coordination abilities, reaction time, handball skills.

Introduction

$\mathrm{T}$ he success of a sports team depends on the effectiveness of the actions of individual players, as well teamwork. Proper assessment of both individual and team actions, which may lead to good teamwork is the basis of the training process (Andrzej Szwarc 2007).

Handball is a sport that demands a high level of coordination. The term "coordination" has been defined as the ability to perform complex motor exercises. Hirtz (1997) suggested a list of 5 basic elements of coordination: reaction, rhythm, balance, kinesthetic differentiation and space - time orientation

These elements don't manifest separately during motor performance, but occur in a complex manner in relation to other physical variables such as speed, strength, endurance and flexibility. Due to the multifaceted nature of coordination, its development is also associated with the development of the associated physical and skill qualities (Abdel Fattah, 1997).

Rakers (1990) divided coordination abilities into physical abilities, sport motor performance abilities and mixed abilities. These abilities are considered the foundation for reaching optimal performance.

Coordination abilities are the back bone of sports specific technical kills. Mastering motor skills, along with coordination abilities is essential in order to perform the movement in its correct course in terms of suitable power, speed, timing and rhythm (Abd El-Maksoud, 1986). Moreover, Jadach (2006) found that the coordination abilities are of the most important. Hockey, (1983) found that mastering the coordination motor abilities facilitates the development of the motor skills, therefore the coordination abilities are essential and necessary for all sports and will improve performance leading to better results. In addition, Stanistaw and Duda (2005) found that developing the coordination abilities plays an important role in achieving the best results due to the correlation between the coordination abilities and motor skills, where the coordination abilities are the basis for the acquisition of motor skills.

According to Alexandru and Acsinte (2005) all of the coordination abilities are utilized during a game of handball:

Control ability: the evaluation of the information (teammate - ball - opponent) and the accurate estimation of the following movement;

- Rhythm ability: integrating the actions in time and free-will actions;

- Differentiation ability: kinesthetic, the movement action is distinguished and evaluated under the influence of the nervous system; 
- Balance ability: to insure a correct position of the body during the motion actions (technical-tactical methods);

- Reaction ability: should react as quickly as possible during the technical-tactical game actions;

- Ability of combining and matching the movements: performance of complex actions made up of many tactical methods or situations.

Space orientation ability: temporal, determination of the court area, of the teammate's position, of the moment when the opponent takes action.

- Anticipation ability: to foresee the actions that are going to follow.

- Ability of changing the movements: the quick transition from some gestures and actions to others (even before the first one has finished).

Although coordination abilities have been shown to be essential to performance and the development of optimal handball skills, the results of this study showed variation in the performance of basic skills among female youth handball players. This variability is due to a lack of special coordination abilities, due to the fact that the Egyptian coaches concentrate only on the development of the physical abilities without any attention to coordination abilities.

In addition, the effectiveness of coordination training in sports was supported by the results of experimental studies carried out in basketball players (Zwierko et al., 2005), handball players (Lidor, et al., 1998), football players (men and women) (Witkowski 2003; Witkowski and Ljach, 2004), volleyball players, kick boxers, tae kwon do participants, single combats (Greco-Roman and free-style wrestling) participants (Gierczuk, 2004) and judo participants (Pietrow, 1997). However, there have been no studies in young athletes.

The aim of this study was to define the coordination abilities that are the most important in handball and to identify whether a coordination training program will improve the performance of basic handball skills among young female athletes.

\section{Material and Methods}

\section{Identification of coordination abilities}

In order to identify the coordination abilities that are the most important in Handball players, questionnaires were given to 10 expert handball coaches. They were asked to evaluate the coordination abilities from the most important to the least important for handball players. Based on these results the two most significant abilities were selected as tennis specific coordination abilities and an intervention program was planned. The coordination abilities considered were:

1. Performance accuracy
2. Ability to change direction

3. Quickness in response

4. Making the effort appropriate to power

5. Making the effort appropriate to time

6. Assessing the situation

7. Motor linking

8. Adapting to changing situations

\section{Intervention Program}

Based on the results from the questionnaires, the coordination program was designed to offer practice in eight abilities. The intervention was a specific training program designed to develop coordination to be performed before the handball training session for twelve weeks, three times per week. In each session the participants practiced three drills for four minutes each. Special attention was given to make the drills fun and appropriate for athletes' age and training experience.

\section{Participants}

The present study included 20 young female handball players, less than 12 year of age $(10.03 \pm 1.6$ years $)$. The participants had one year of experience in handball. These individuals voluntarily participated in this experiment.

\section{Procedures}

Subjects were assessed before and after 12-weeks training program Tests followed a general warm-up that consisted of running, calisthenics, and stretching.

\section{$\underline{\text { Coordination abilities tests }}$}

- Performance accuracy (Shooting on the numbered targets)

- Changing direction (dribble in different directions)

- Quickness of response (passing according to single)

- Making the effort appropriate to power (grip strength via dynamometer)

- Making the effort appropriate to time shooting from high in time

- Assessing the situation (shooting according to single)

- Motor linking (connected between defense skills and offensive skills)

- Adapting to changing situations (release from offensive to defense)

\section{$\underline{\text { Skills tests }}$}

- Passing (to $30 \mathrm{~s}$ )

- Dribble (to $30 \mathrm{~m}$ )

- $\quad$ Shooting (jump shoot) 
- Defensive Movements (movement to front and back and both sides)

\section{Statistical Analysis}

All statistical analyses were calculated by the SPSS statistical package. The results are reported as means and standard deviations (SD). Differences between pre and posttests were reported as mean difference $\pm 95 \%$ confidence intervals (mean diff $\pm 95 \% \mathrm{CI}$ ). Student's t-test was used to determine the differences in skills and physical parameters between pre and posttests. A $p<0.05$ was considered to be statistically significant.

Results

Table 1

Coordination Abilities and Skills

\begin{tabular}{|c|c|c|c|c|c|}
\hline \multirow{2}{*}{ Abilities/Skills } & \multirow{2}{*}{$\begin{array}{c}\text { Measurement } \\
\text { units }\end{array}$} & \multicolumn{3}{|c|}{ Experimental } & \multirow{2}{*}{ T sign } \\
\cline { 3 - 5 } & & pre & post & \multirow{2}{*}{ change\% } & \\
\hline Performance Accuracy & Degree & $\mathbf{2 . 5 5} \pm \mathbf{1 . 1 5}$ & $\mathbf{4 . 6 5} \pm \mathbf{1 . 4 6}$ & $\mathbf{7 . 1 0}$ & Sign \\
\hline Changing Direction & Seconds & $\mathbf{1 5 . 0 6} \pm \mathbf{1 . 8 6}$ & $\mathbf{1 3 . 6 7} \pm \mathbf{1 . 9 0}$ & $\mathbf{1 . 6 3}$ & Sign \\
\hline Quickness of Response & Seconds & $\mathbf{4 . 9 3} \pm \mathbf{2 . 3 5}$ & $\mathbf{2 . 7 0} \pm 1.59$ & $\mathbf{7 . 3 6}$ & Sign \\
\hline Making the effort appropriate to power & Kilogram & $\mathbf{5 . 3 7} \pm \mathbf{1 . 4 4}$ & $\mathbf{3 . 6 5} \pm 1.06$ & $\mathbf{4 . 9 4}$ & Sign \\
\hline Making the effort appropriate to time & Seconds & $\mathbf{4 . 8 0} \pm \mathbf{2 . 8 2}$ & $\mathbf{1 . 7 5} \pm 1.99$ & $\mathbf{7 . 1 0}$ & Sign \\
\hline Assess the situation & Degree & $\mathbf{4 . 9 0} \pm \mathbf{3 . 3 2}$ & $\mathbf{9 . 3 5} \pm \mathbf{3 . 3 0}$ & $\mathbf{1 3 . 1 9}$ & Sign \\
\hline Motor linking & Seconds & $\mathbf{2 9 . 5 5} \pm \mathbf{3 . 2 0}$ & $\mathbf{2 7 . 8 5} \pm \mathbf{2 . 8 9}$ & $\mathbf{3 . 7 0}$ & Sign \\
\hline Adapting to Changing Situations & Seconds & $\mathbf{1 8 . 9 9} \pm \mathbf{1 . 9 6}$ & $\mathbf{1 6 . 5 4} \pm \mathbf{1 . 8 0}$ & $\mathbf{1 7 . 5 7}$ & Sign \\
\hline Passing & Frequency & $\mathbf{2 2 . 1 0} \pm \mathbf{2 . 7 5}$ & $\mathbf{3 0 . 6 5} \pm \mathbf{2 . 4 7}$ & $\mathbf{1 0 . 8 5}$ & Sign \\
\hline Dribbling & Seconds & $\mathbf{1 6 . 1 0} \pm \mathbf{2 . 3 0}$ & $\mathbf{1 3 . 9 4} \pm \mathbf{2 . 0 4}$ & $\mathbf{1 3 . 1 9}$ & Sign \\
\hline Shooting & Degree & $\mathbf{1 . 7 5} \pm \mathbf{1 . 2 5}$ & $\mathbf{3 . 1 0} \pm 1.12$ & $\mathbf{7 . 3 6}$ & Sign \\
\hline Defensive movements & Seconds & $\mathbf{2 8 . 5 2} \pm \mathbf{3 . 5 0}$ & $\mathbf{2 5 . 3 9} \pm \mathbf{3 . 3 3}$ & $\mathbf{4 . 9 4}$ & Sign \\
\hline
\end{tabular}

Table 1 shows statistically significant differences between the pre and posttests in all of variables for posttests.

Table 2

Correlation Coefficient between Coordination Abilities and Handball Skills

\begin{tabular}{|c|c|c|c|c|}
\hline Abilities & Passing & Dribbling & Shooting & $\begin{array}{c}\text { Defensive } \\
\text { Movements }\end{array}$ \\
\hline Performance Accuracy & $\mathbf{0 . 0 5 7}$ & $\mathbf{0 . 3 4 9}$ & $* \mathbf{0 . 6 0 2}$ & $\mathbf{0 . 4 1 4}$ \\
\hline Changing Direction & $\mathbf{- 0 . 3 2 1}$ & $* 0.566$ & $\mathbf{- 0 . 4 0 4}$ & $* 0.495$ \\
\hline Quickness of Response & $\mathbf{- 0 . 1 6 0}$ & $\mathbf{0 . 1 4 5}$ & $\mathbf{0 . 2 3 4}$ & $\mathbf{0 . 0 0 5}$ \\
\hline Making the effort appropriate to power & $\mathbf{- 0 . 0 3 5}$ & $\mathbf{0 . 0 1 7}$ & $\mathbf{0 . 1 4 7}$ & $\mathbf{- 0 . 1 3 1}$ \\
\hline Making the effort appropriate to time & $\mathbf{- 0 . 1 7 6}$ & $\mathbf{0 . 3 8 0}$ & $\mathbf{- 0 . 6 3 4}$ & $\mathbf{0 . 4 2 1}$ \\
\hline Assess the situation & $* \mathbf{0 . 4 5 6}$ & $\mathbf{- 0 . 2 5 3}$ & $\mathbf{0 . 3 6 1}$ & $\mathbf{0 . 0 1 6}$ \\
\hline Motor linking & $\mathbf{- 0 . 0 3 9}$ & $\mathbf{0 . 4 1 4}$ & $\mathbf{- 0 . 4 1 1}$ & $* 0.581$ \\
\hline Adapting to Changing Situations & $\mathbf{- 0 . 2 5 2}$ & $\mathbf{0 . 0 2 0 7}$ & $*_{-0.495}$ & $* 0.663$ \\
\hline
\end{tabular}

$* 0.05=0.444$

Table (2) shows that the values of the correlation coefficients are statistically significant for 7 abilities.

\section{Discussion}

Coordination abilities are essential in order to develop and perform optimal handball skills, as well as the movement techniques (Bourqouin, 2003). The aim of the present study was to define the coordination abilities that the most important in handball and to identify whether a coordination training program will improve the performance of basic handball skills among young athletes. The results of this study supported the theory that coordination abilities are basic elements for athletic skills. Furthermore, practicing those abilities with specific exercises improved performance (Druckman \& Swets, 1988).
The training program contained a variety of exercises, appropriate for the age of the participants, to develop the coordination abilities and skills determined to be important in handball. The program progressed from easy to difficult, with repetition and training integrated with the skills of the game. This is consistent with the findings of Mohamed Lotfy (2006), the procedures which used to development of coordination performance should be constant with movements in a short time.

The results of this study are consistent with the results of studies by Nermin \& Dalia (2005), Khaled (2007), and Khaled \& Susan (2008) in that the coordination training 
program had a positive impact on the development of coordination abilities and basic handball skills.

Essam El-Din Abdel-Khalek (2005) and Mohamed Lotfy (2006) indicated that the coordination abilities facilitate the development of skills related to sports.

In regards to the relationship between coordination abilities and performance level, Schreiner (2000) found that these coordination abilities are considered the key to success in learning dynamic skills and improving the training plan, skill and physical level of performance. When a player has mastered these abilities, he or she may raise the level of performance, thus, they are directly proportional to technical performance.

\section{Practical Applications}

Coordination abilities are important for performance during handball and their development from the early age is essential. Specifically, coaches who work with young players should include coordination exercises in their daily training program.

\section{References}

1. Abd El-Maksoud, E. Movement Theories. Dar Elfekr Elaraby, Cairo, 29.1986.

2. Abdel Fattah, AA. Sports training and physiological fundamentals. Dar Elmaaref, Cairo, 235,1997.

3. Alexandru E, Acsinte A. Handbal, Mijloace de acţionare, Ed. Valinex, Chişinău,102,2005.

4. Bourqouin, O. Coordination. In: Strength and Conditioning for tennis, A.Q. Machar Reid, and Miguel Crespo. International Tennis Federation, ITF Ltd, 71-77,2003.

5. Druckman D, Swets, JA. Enhancing human performance. Washington: Washington: National Academy Press.23,1988.

6. Essam El-Din A. Sports Coaching (theories and applications), edition of 12, established knowledge, Cairo, 98,2005

7. Gierczuk, D. Coordination Training as a Factor Streamlining of the Goal-Oriented and Special Stage during the Schooling of Wrestlers, 2004. available at .

8. Hockey RV. Physical Fitness-pathway to healthful living. Mosby Company, 4th Ed., 294,1983.

9. Jadach, A. Psychomotor abilities in female handball players at various performance levels. Research Yearbook Studies in Physical Education and Sport, 2006; 13: 77-82.
10. Khaled F. The impact of quality exercise program for capacity development on the harmonic aspects of attention and some level of technical performance of beginners judo," Faculty of Physical Education journal, Mansoura,2007;3(5)21-30.

11. Khaled $R$. The effectiveness of a proposed program of interoperability capabilities and their relationship to the skill level of volleyball players under 14 years. Journal of Sports Science and Arts, 2008;55(2):24-30

12. Lidor R, Argov E, Daniel S. An exploratory study of perceptual-motor abilities of women: novice and skilled players of team handball. Perceptual and Motor Skills, 1998:86, 279 - 288.

13. Mohamed L. Sports achievement and performance rules, Center for the Book Publishing, Cairo.39,2006.

14. Nermin fekry and Dalia Orabi (2005): The effectiveness of a proposed program for some harmonic capacity and its relationship to the performance of some offensive skills in junior basketball", published research, Journal of Contemporary Psychology and Humanities, 2005; 16, 88-94.

15. Pietrow AM. Centralnoje programmirowanie mechanizmow realizacji koordinacjonnych sposobnostej sportsmenow $i$ ich pedagogiczeskoje obosnowanie. Awtoref. siss. dokt.ped.nauk. Moskwa. 48 ,1997.

16. Rakers G. Learning and Coordination Skills. Publishing house, Rome, 291,1990

17. Schreiner P. Koordinations Training Fussball, das Peter Schreiner System.Rowohlt Verlag, Reinbek, 10-27,2000.

18. Stanistaw Z, Duda H. Coordinating ability but efficiency of game of young football players. Team games in physical education and sport. Academy of physical education, Cracow, Poland, 284,2005.

19. Witkowski Z. Koordinacjonnyje sposobnosti junych futbolistow: diagnostika, struktura, ontogenez (praca doktorska) (in Russian). Moskwa. 232,2003

20. Witkowski Z, Ljach W. Cwiczenia ksztaltujace koordynacyjne zdolnosci motoryczne $w$ pilce noznej. Centralny Osrodek Sportu, Warszawa. $198,2004$.

21. Zwierko T, Lesiakowski $P$, Florkiewick $B$. (2005). Selected aspects of motor coordination in young basketball players. Human Movement Science, 2005; 6: 124-128. 
